\title{
Pengembangan Sistem Informasi Pembelian, Penjualan dan Persediaan Motor Bekas menggunakan Analisis Fast-Slow-Non Moving
}

\author{
http://dx.doi.org/10.28932/jutisi.v6i3.3100
}

\author{
Renaldy\#1, Teddy Marcus Zakaria. ${ }^{\bowtie * 2}$ \\ ${ }^{1}$ renaldywang99@gmail. com \\ "Teknik Informatika, Universitas Kristem Maranatha \\ Jl. Prof. drg. Suryasumantri No.65, Bandung \\ ${ }^{2}$ teddy. marcuseit.maranatha. edu
}

\begin{abstract}
Motorcycle Company is engaged in selling used motorcycles, processing motorcycle inventory data to manage the optimal number of purchases and sales. Based on monthly sales data, we can predict the need to buy a used vehicle from the seller. Through FSN (Fast-moving, Slow-moving, and Nonmoving) analysis has to consider quantity, the rate of consumption of item and how often they are issued or used. The results of analysis can be used to guide the decision of the right amount of inventory to be placed in the warehouse, the frequency to buy or even delete certain items in stages. In order for the FSN analysis to be carried out successfully, it is necessary to analyze the items based on their respective categories, within a certain period of time. The purpose of this research is to design and build an information system for the sale of used motor vehicles, purchase of used motorcycles by considering the optimal inventory using the FSN method.
\end{abstract}

Keywords - Inventory Management; Selling-buying Used Motorcycle; Fast-moving Slow-moving and Non-moving Anylysis.

\section{Pendahuluan}

Perusahaan Motor Bekas bergerak dalam bidang penjualan motor bekas, mengolah data persediaan motor untuk mengatur jumlah pembelian dan penjualan yang optimal. Proses Jual-Beli motor bekas adalah proses dimana moda usaha yang melakukan transaksi pembelian motor bekas dari perorangan maupun dari penjual lainnya. Proses selanjutnya ialah menjual kembali motor bekas tersebut secara langsung atau melalui proses perbaikan terlebih dahulu jika kondisi motor bekas tersebut tidak memungkinkan untuk langsung dipasarkan kembali [1].

Berdasarkan data penjualan setiap bulannya dapat diprediksi kebutuhan untuk membeli kendaraan bekas kepada penjual. Data yang diolah meliputi jenis pabrikan motor, tahun produksi, model motor, jenis pembayaran.
Kegiatan pengolahan data berupa pendataan motor yang dibeli, pendataan penjual motor, pencatatan transaksi pembelian, penjualan, biaya perbaikan dan sebagainya. Laporan pembelian, penjualan dan persediaan, perlu disajikan secara periodik.

Analisis terhadap persediaan lebih seksama diperlukan terutama untuk membedakan item yang bergerak cepat, lambat, dan tidak bergerak (FSN/Fast-Slow-Non Moving) [5], [6]. Tujuan analisis FSN untuk mempertimbangkan kuantitas, tingkat konsumsi item dan seberapa sering item dikeluarkan atau dijual. Hasil analisis ini dapat digunakan untuk memandu keputusan jumlah persediaan yang tepat untuk ditempatkan di gudang, frekuensi untuk membeli atau bahkan menghapus item tertentu secara bertahap. Agar analisis FSN dapat dilaksanakan dengan sukses, diperlukan analisis yang terhadap item berdasarkan kategori masingmasing, dalam suatu kurun waktu tertentu. [6]

Berdasarkan latar belakang permasalahan tersebut, sebuah perusahaan penjualan kendaraan motor bekas, memerlukan sebuah sistem untuk mengakomodasi pencatatan transaksi penjualan, pembelian dan persediaan barang dengan mempertimbangkan pergerakan item barang. Melalui sistem ini diharapkan dapat memandu keputusan manajemen untuk mengontrol jumlah persediaan yang optimal. Analisis persediaan barang dapat dilakukan secara berkala untuk mempermudah pengaturan stok gudang agar tidak berlebih atau kurang [7].

Adapun tujuan dari penelitian ini adalah merancang dan membangun sebuah sistem informasi untuk pembelian, penjualan dan persediaan kendaraan motor bekas dengan mempertimbangkan optimasi FSN. 


\section{TINJAUAN PUSTAKA}

\section{A. Pengontrolan Persediaan Moda Usaha}

Pengontrolan persediaan didefinisikan sebagai usaha atau cara yang dilakukan suatu moda usaha agar dapat memaksimalkan kapasitas penyimpanan disertai dengan proses jual-beli yang optimal [1], [4]. Pengontrolan persediaan dapat berupa pembatasan terhadap pembelian stok atau penyimpanan barang di gudang. Variasi pengontrolan persediaan sering disebut juga sebagai pengaturan penyimpanan [4].

Pengontrolan persediaan sering dianggap tidak penting oleh banyak moda usaha. Sedangkan pada realitanya pengontrolan ini dapat berdampak besar pada proses usaha yang dilakukan karena jika pengontrolan diabaikan maka dampak yang akan terasa langsung ialah sering kehabisan stok saat dibutuhkan atau penuhnya ruang penyimpanan dikarenakan oleh penumpukan stok yang kurang diminati oleh pasar [3]. Contoh lainnya adalah terjadinya kehilangan atau kesalahan pencatatan stok barang yang ada di penyimpanan (inventory). Selain itu, potensi kerusakan barang akibat disimpan terlalu lama dapat menimbulkan adanya pengurangan nilai jual barang tersebut. Kehilangan nilai jual barang juga dapat terjadi jika model atau tipe barang tersebut sudah tertinggal oleh tren barang yang baru. Intinya, semakin lama barang tersebut tidak terjual maka semakin turun nilai jual barang tersebut [4], [9].

\section{B. Proses Jual-Beli Motor Bekas}

Proses Jual-Beli motor bekas adalah proses dimana seseorang atau satu moda usaha yang melakukan transaksi pembelian motor bekas dari perorangan maupun dari penjual lainnya [3]. Proses selanjutnya ialah menjual kembali motor bekas tersebut secara langsung atau melalui proses perbaikan terlebih dahulu jika kondisi motor bekas tersebut tidak memungkinkan untuk langsung dipasarkan kembali.

Analisis tingkat penjualan setiap tipe motor bekas dapat membantu pemilik usaha dalam hal memutuskan untuk membeli motor bekas tersebut untuk dijual kembali atau tidak. Jika keputusan pemilik kurang tepat, berpotensi terhadap penumpukan stok di penyimpanan yang dapat berakibat habisnya modal usaha [1], [4]. Penumpukan stok dalam waktu panjang pun dapat berakibat kepada penurunan nilai jual barang (tertinggal model baru, kerusakan karena penyimpanan yang lama atau berkarat) [12]. Atau sebaliknya, bila kekurangan stok, potensi keuntungan menjadi hilang, saat ada konsumen membutuhkan motor bekas tersebut.

\section{Penelitian Terkait}

Penelitian Muhsin [1], sistem informasi penjualan motor bekas mencatat data pembelian barang, stok barang, data penjualan barang serta laporan penjualan yang terjadi setiap harinya. Sistem ini yang memberikan informasi yang bermanfaat kepada pihak manajemen UD.Merdeka, yaitu data penjualan, pembelian yang terintegrasi dan jauh lebih efisien dibandingkan dengan pencatatan manual. Adanya fitur untuk mencari data motor yang diinginkan secara cepat dan akurat, laporan keluar masuk barang setiap bulannya, ini menjadi kelebihan sistem ini.

Penelitian Minarni [2], sistem informasi penjualanpembelian sebagai sarana promosi yang dibangun memiliki kelebihan yaitu statistik mobil terjual dalam suatu periode dan jumlah mobil yang diiklankan.

Sistem Informasi Penjualan yang dikembangkan oleh Wimmie [3], dapat mengetahui atribut yang paling berpengaruh dalam penjualan sepeda motor berdasarkan data yang telah tersedia, menggunakan algortima C4.5. Data atribut sepeda motor yang telah ditentukan yaitu merk, jenis, warna, dan tahun, akan diolah sehingga dihasilkan daftar nilai gain dari tiap atribut. Atribut dengan nilai gain paling tinggi, menunjukkan kebutuhan pasar.

Penelitian Lieberty [13], pada PD. Padalarang Jaya, merancang sistem untuk mencatat setiap transaksi penjualan dan pembelian tersimpan di database komputer. Sistem informasi ini juga dapat melakukan peramalan yang berguna untuk meramalkan berapa banyak barang yang terjual dalam beberapa periode tertentu atau jumlah barang yang mungkin akan terjual di bulan berikutnya.

\section{Fast Moving, Slow Moving, Non Moving (FSN)}

Pengontrolan inventory berdampak besar pada proses usaha, salah satu analisis pergerakan barang yaitu FSN Analysis [6]. Janari, dalam penelitiannya menggunakan metoda 3D yaitu analisis FSN (tingkat konsumsi) dikombinasikan dengan analisis ABC (berbasis nilai), dan SDE (lead time).untuk mengendalikan persediaan di PT. Semen Indonesia [4].

1) Tujuan dari analisis FSN adalah untuk mempertimbangkan kuantitas, tingkat konsumsi suatu produk dan seberapa sering produk itu terjual dan menggunakan informasi ini untuk membimbing keputusan tentang penempatan di gudang (mempertimbangkan biaya penyimpanan dan perawatan untuk menghemat waktu dan tenaga kerja) [6]. Untuk memastikan keberhasilan dilaksanakannya analisis FSN maka memerlukan analisis terhadap seluruh produk dengan cara dibagi ke dalam kategori masing-masing. Hal ini dilakukan dengan memastikan informasi tertentu seperti rata-rata stok di persediaan dan tingkat penjualan produk tersebut dan melakukan analisis dalam jangka waktu tertentu [7]. Setelah rata-rata ditetapkan dan tingkat konsumsi telah dihitung untuk setiap produk di dalam persediaan, rata-rata waktu tinggal dan tingkat konsumsi dapat dihitung dengan 
persentase dari total stok penyimpanan. status $\mathrm{F}, \mathrm{S}$ dan $\mathrm{N}$ dapat dihitung. Rata-rata menginap dan tingkat konsumsi dapat dihitung ketika diperintahkan dalam urutan dan sesuai dengan Rumus 1.

Rata-rata Perputaran = Permintaan Tahunan Persediaan Rata-Rata

Setelah itu penggunaan tahunan setiap item dihitung diikuti dengan perhitungan persentase penggunaan tahunan setiap item. Penggunaan tahunan dihitung dari Rumus 2.

Penggunaan Tahunan setiap item = Permintaan

Tahunan setiap item $x$ Harga Satuan setiap item.

Setelah ini, persentase penggunaan kumulatif setiap item dihitung. Persentase penggunaan kumulatif dihitung dari Rumus 3.

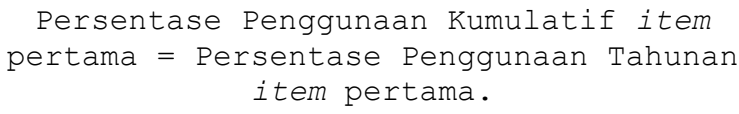

Kemudian dilanjutkan dengan Rumus Persentase Penggunaan Kumulatif Item ke-2, seperti pada Rumus 4 dan seterusnya :

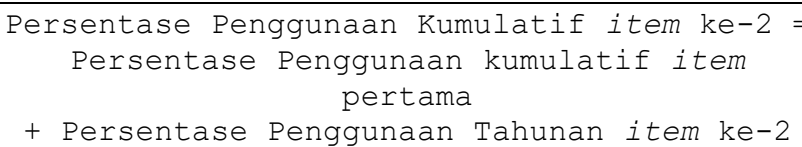

2) FSN Classification: Klasifikasi FSN merupakan klasifikasi dengan mengelompokkan material berdasarkan laju konsumsi suatu material [6],[7]. Terdapat tiga tingkatan dalam FSN analisis. Tingkatan untuk masing-masing kategori adalah sebagai berikut :

- F (Fast Moving) lebih dari rata-rata dalam kurun waktu yang ditentukan [8].

- S (Slow Moving) sama dengan rata-rata dalam kurun waktu yang ditentukan.

- $\quad \mathrm{N}$ (Non-Moving) kurang dari rata-rata dalam kurun waktu yang ditentukan.

3) Keuntungan Menggunakan Metode FSN: Dasar analisis FSN adalah untuk mendapatkan data vital untuk membantu membuat keputusan manajemen inventory [5]. Hal itu termasuk di manakah suatu produk harus ditempatkan di dalam gudang penyimpanan. Misalnya, item yang masuk kategori fast moving dapat ditempatkan di lokasi yang mudah diakses. Hal ini juga dapat membantu menentukan barang mana yang merupakan non-moving dan membutuhkan biaya untuk menyimpannya, dan barang apa yang mungkin memerlukan perubahan rencana pembelian dikarenakan barang tersebut masuk kedalam kategori slow moving. Saat membuat keputusan untuk inventory, penting untuk menganalisis data yang ada dan melakukan perhitungan untuk memastikan hasil terbaik dalam hal penawaran dan permintaan [8]. Untuk memperoleh data ini atau mengelola inventory secara umum, penting untuk membuat sistem manajemen inventory, yang dirancang khusus untuk tujuan ini.

4) Studi Kasus dilakukan pada CV. Antar Putera, Lembang, data penjualan mokas sebanyak 395 transaksi periode 2 Juli 2018 - 21 Januari 2019, data jenis kendaraan 43 jenis. Data permintaan tahunan motor bekas menggunakan metode FSN. Proses perhitungan dilakukan 2 tahapan.

a. Hitung persentase permintaan tahunan \& persentase kumulatif permintaan tahunan, tertera pada Tabel I

b. Klasifikasi barang inventaris ke dalam kelas F, S \& N. Range FSN yang digunakan dalam contoh ini adalah $\mathrm{F}(15 \%), \mathrm{S}(35 \%)$, dan $\mathrm{N}(50 \%)$, tertera pada Tabel II.

TABEL I

PERMINTAAN KENDARAAN TAHUNAN

\begin{tabular}{|c|c|c|c|}
\hline No & Item & $\begin{array}{l}\text { Harga Rata- } \\
\text { rata }\end{array}$ & $\begin{array}{l}\text { Permin- } \\
\text { taan } \\
\text { Tahunan }\end{array}$ \\
\hline 1. & $\begin{array}{l}\text { Yamaha } \\
\text { NMax }\end{array}$ & Rp.19.000.000 & 60 \\
\hline 2. & $\begin{array}{l}\text { Yamaha } \\
\text { Mio Z }\end{array}$ & Rp.10.000.000 & 24 \\
\hline 3. & $\begin{array}{l}\text { Honda Soul } \\
125\end{array}$ & Rp.12.000.000 & 20 \\
\hline 4. & $\begin{array}{l}\text { Honda } \\
\text { Vario } 150\end{array}$ & Rp.15.000.000 & 20 \\
\hline 5. & $\begin{array}{l}\text { Honda } \\
\text { Vario } 125\end{array}$ & Rp.13.000.000 & 18 \\
\hline 6. & $\begin{array}{l}\text { Honda } \\
\text { Scoopy }\end{array}$ & Rp.12.500.000 & 18 \\
\hline 7. & Honda Beat & Rp.11.000.000 & 17 \\
\hline 8. & $\begin{array}{l}\text { Kawasaki } \\
\text { Ninja } 150\end{array}$ & Rp.15.000.000 & 16 \\
\hline 9. & $\begin{array}{l}\text { Kawasaki } \\
\text { Ninja } 250\end{array}$ & Rp.25.000.000 & 15 \\
\hline 10. & $\begin{array}{l}\text { Yamaha } \\
\text { Aerox }\end{array}$ & Rp.14.000.000 & 13 \\
\hline 11. & $\begin{array}{l}\text { Yamaha } \\
\text { Jupiter MX }\end{array}$ & Rp.13.000.000 & 13 \\
\hline 12. & $\begin{array}{l}\text { Yamaha } \\
\text { Vixion }\end{array}$ & Rp.16.000.000 & 13 \\
\hline 13. & Suzuki GSX & Rp.18.000.000 & 12 \\
\hline
\end{tabular}




\begin{tabular}{|c|l|c|c|}
\hline 14. & $\begin{array}{l}\text { Suzuki } \\
\text { Satria }\end{array}$ & Rp.12.000.000 & 12 \\
\hline 15. & $\begin{array}{l}\text { Suzuki } \\
\text { Shogun }\end{array}$ & RP.10.000.000 & 12 \\
\hline
\end{tabular}

TABEL II

HASIL PERHITUNGAN KATEGORI FSN

\begin{tabular}{|c|c|c|c|c|c|}
\hline $\begin{array}{l}\mathbf{N} \\
\mathbf{0}\end{array}$ & Item & $\begin{array}{c}\text { Permin- } \\
\text { taan } \\
\text { Tahunan }\end{array}$ & $\begin{array}{c}\% \\
\text { Permin- } \\
\text { taan } \\
\text { Tahunan } \\
\end{array}$ & $\begin{array}{c}\text { Total } \\
\text { Persen- } \\
\text { tase }\end{array}$ & $\begin{array}{c}\text { Kate- } \\
\text { gori }\end{array}$ \\
\hline 1 & $\begin{array}{l}\text { Yamaha } \\
\text { NMax }\end{array}$ & 60 & 21.2 & 21.2 & $\mathrm{~F}$ \\
\hline 2 & $\begin{array}{l}\text { Yamaha } \\
\text { Mio Z }\end{array}$ & 24 & 8.48 & 29.68 & $F$ \\
\hline 3 & $\begin{array}{l}\text { Honda } \\
\text { Soul } 125\end{array}$ & 20 & 7.07 & 36.75 & $S$ \\
\hline 4 & $\begin{array}{l}\text { Honda } \\
\text { Vario } \\
150\end{array}$ & 20 & 7.07 & 43.82 & $S$ \\
\hline 5 & $\begin{array}{l}\text { Honda } \\
\text { Vario } \\
125\end{array}$ & 18 & 6.36 & 50.18 & $S$ \\
\hline 6 & $\begin{array}{l}\text { Honda } \\
\text { Scoopy }\end{array}$ & 18 & 6.36 & 56.54 & S \\
\hline 7 & $\begin{array}{l}\text { Honda } \\
\text { Beat }\end{array}$ & 17 & 6.01 & 62.55 & $S$ \\
\hline 8 & $\begin{array}{l}\text { Kawasak } \\
\text { i Ninja } \\
150\end{array}$ & 16 & 5.65 & 68.2 & $\mathrm{~N}$ \\
\hline 9 & $\begin{array}{l}\text { Kawasak } \\
\text { i Ninja } \\
250 \\
\end{array}$ & 15 & 5.31 & 73.51 & $\mathrm{~N}$ \\
\hline 10 & $\begin{array}{l}\text { Yamaha } \\
\text { Aerox }\end{array}$ & 13 & 4.59 & 78.10 & $\mathrm{~N}$ \\
\hline 11 & $\begin{array}{l}\text { Yamaha } \\
\text { Jupiter } \\
\text { MX }\end{array}$ & 13 & 4.59 & 82.69 & $\mathrm{~N}$ \\
\hline 12 & $\begin{array}{l}\text { Yamaha } \\
\text { Vixion }\end{array}$ & 13 & 4.59 & 87.28 & $\mathrm{~N}$ \\
\hline 13 & $\begin{array}{l}\text { Suzuki } \\
\text { GSX }\end{array}$ & 12 & 4.24 & 91.52 & $\mathrm{~N}$ \\
\hline 14 & $\begin{array}{l}\text { Suzuki } \\
\text { Satria }\end{array}$ & 12 & 4.24 & 95.76 & $\mathrm{~N}$ \\
\hline 15 & $\begin{array}{l}\text { Suzuki } \\
\text { Shogun }\end{array}$ & 12 & 4.24 & 100 & $\mathrm{~N}$ \\
\hline
\end{tabular}

Keterangan kolom : "No" untuk mengetahui jumlah jenis motor yang tersedia. Kolom "Item" untuk mengetahui nama jenis motor. Kolom "Permintaan Tahunan" digunakan untuk mengetahui permintaan tahunan masing-masing jenis motor. Kolom “\% Permintaan Tahunan" untuk mengetahui persentase permintaan tahunan masing-masing jenis motor terhadap jumlah keseluruhan permintaan tahunan. Kolom "Total Persentase" untuk mengetahui apakah jumlah permintaan sesuai dengan total keseluruhan permintaan tahunan. Didapatkan dengan cara menjumlahkan setiap persentase permintaan tahunan dengan total persentase tahunan sebelumnya menggunakan Rumus Persentase Penggunaan Kumulatif Item Pertama dan Rumus Persentase Penggunaan Kumulatif Item Pertama ke-2. Kolom "Kategori" untuk mengetahui pembagian kelas setiap masing-masing jenis motor. Ditentukan melalui perhitungan parameter yang sudah ditentukan (Range FSN) terhadap jumlah jenis motor yang tersedia.

\section{ANALISIS DAN RANCANGAN SISTEM}

Metoda penelitian yang digunakan adalah Analisis Kebutuhan Sistem, Proses Bisnis Sistem terdiri dari Pembelian-Analisis FSN dan Penjulan, rancangan berbasis objek menggunakan UML (Unified Model Language) [10], [11], [12].

\section{A. Analisis Kebutuhan Sistem}

Sistem yang dibutuhkan selain mencatat data kendaraan, pembelian, penjualan, dan persediaan, akan ditambahkan sistem pendukung yang dapat menganalisis persediaan kendaraan motor bekas menggunakan analisis FSN Harapan pemilik adalah membantu keputusan dalam pengelolaan stok, peletakan posisi kendaraan berdasarkan FSN, apakah perlu melakukan pembelian sesuai analisis perbandingan rata rata penjualan jenis motor tersebut dalam jangka waktu tertentu dengan stok yang masih tersedia.

\section{B. Proses Bisnis Pembelian Motor Bekas}

Proses bisnis dimulai ketika pemilik akan melakukan pembelian motor bekas melalui orang yang menawarkan motor bekas atau pun membeli motor bekas dari penjual motor bekas lainnya.

1. Registrasi pada sistem

Tahap awal, adalah mencatat data penjual motor pada sistem (registrasi), yang dilakukan oleh admin.

2. Analisis data persediaan (FSN)

Setelah tahap registrasi, pengguna dapat mencermati hasil analisis data terhadap data-data yang sudah ada dan dapat melakukan keputusan pemindahan letak produk di gudang atau melakukan pencarian motor yang memerlukan tambahan stok.

3. Pembelian Produk

Jika ada yang menawarkan satu jenis motor maka pengguna dapat memasukkan jenis motor dan sistem akan menganalisis secara otomatis apakah jenis motor tersebut ada di dalam stok dan apakah jenis motor tersebut membutuhkan tambahan stok atau tidak.

4. Pencatatan Pembelian

Jika pengguna memutuskan untuk membeli motor tersebut maka harus dilakukan pencatatan data motor dan data penjual motor serta nominal pembelian dan tanggal transaksi dilakukan. 
5. Status produk

Setelah menyelesaikan proses pembelian maka pengguna dapat menentukan status motor bekas tersebut apa layak langsung untuk dijual kembali apa motor tersebut harus melewati proses perbaikan terlebih dahulu.

\section{Proses Bisnis Penjualan Motor Bekas}

Proses ini dilakukan ketika terjadi transaksi penjualan motor. Peran yang terlibat dalam proses ini ialah pengguna (pegawai), pembeli, dan admin.

1. Pencarian Motor

Sebagai tahap awal, transaksi jual motor bekas terjadi ketika pembeli melakukan pencarian terhadap motor yang diinginkan dan pengguna akan mencari motor yang sesuai pada sistem.

2. Analisis Motor

Jika sistem menemukan kecocokan, tahap selanjutnya sistem akan menampilkan daftar motor yang dicari dan memberi saran kepada pegawai untuk menawarkan produk yang sesuai untuk calon pembeli.

3. Transaksi Penjualan Motor

Jika pembeli setuju untuk membeli motor tersebut maka pengguna akan mencatat data pembeli dan mencatat transaksi yang dilakukan (Motor yang terjual, harga, jenis pembayaran, data pembeli).

\section{Unified Modelling Language (UML)}

Gambar 1 merupakan usecase dari rancangan sistem yang dibangun, dan terdapat peran admin, bagian penjualan dan pembelian dalam sistem Jual Beli dengan FSN Analysis. Fitur-fitur terdiri dari : masuk sebagai pengguna (login), kelola penjualan, kelola pembelian, kelola data list motor, kelola jasa, kelola data penjual, kelola data pembeli, dan keluar dari halaman pengguna (logout).

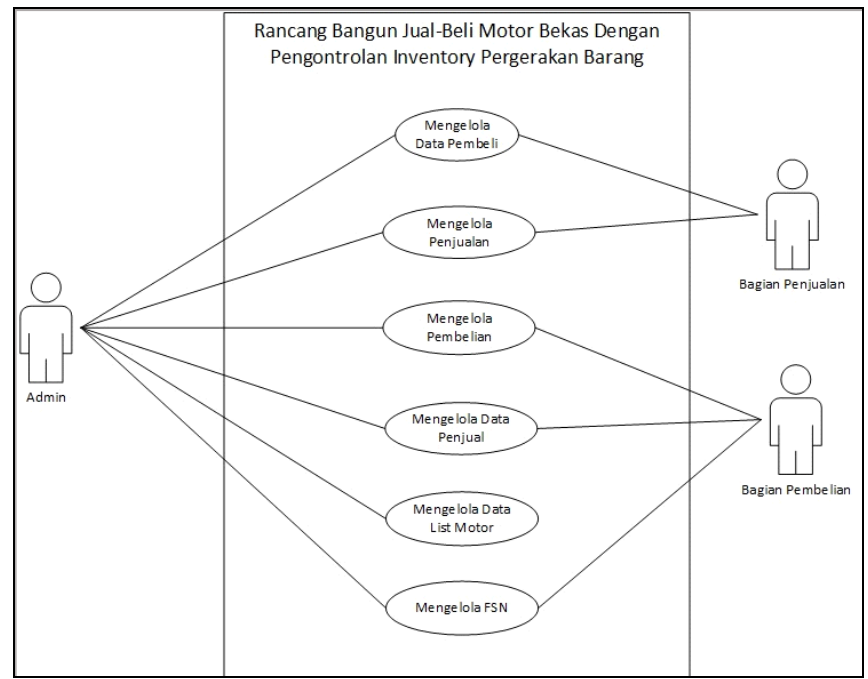

Gambar 1 Use Case Jual-Beli dengan FSN Analysis

\section{a. UML - Diagram Kelola Penjualan}

Deskripsi : Mengelola data penjualan motor bekas pada sistem, seperti pada Gambar 2. Aktor : Pengguna (admin), Bagian Penjualan. Kondisi Awal : Admin, Bagian Penjualan, Bagian Pembelian memilih menu penjualan yang telah tersedia. Kondisi Akhir : Admin dapat menggunakan fitur lihat penjualan, tambah penjualan, ubah penjualan, dan hapus penjualan yang terdapat dalam sistem.

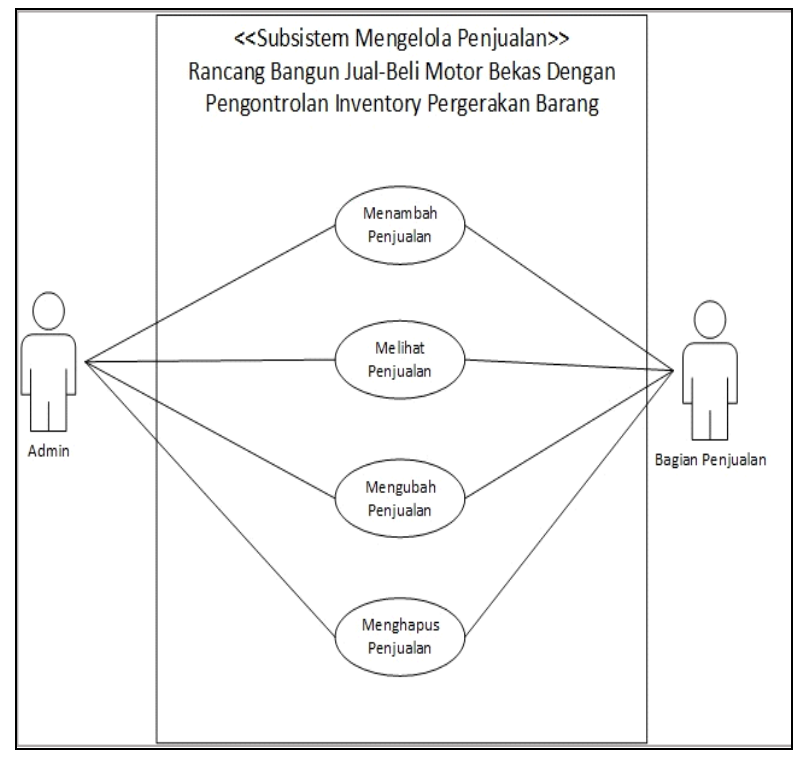

Gambar 2 Diagram Kelola Penjualan

\section{b. UML-Diagram Kelola Pembelian}

Deskripsi : Mengelola data pembelian motor bekas pada sistem, tampak pada Gambar 3. Aktor : Pengguna (admin), Bagian Penjualan, Pembeli. Kondisi Awal : Admin memilih menu pembelian yang telah tersedia. Kondisi Akhir : Admin dapat menggunakan fitur lihat pembelian, tambah pembelian, ubah pembelian, dan hapus pembelian yang terdapat dalam sistem.

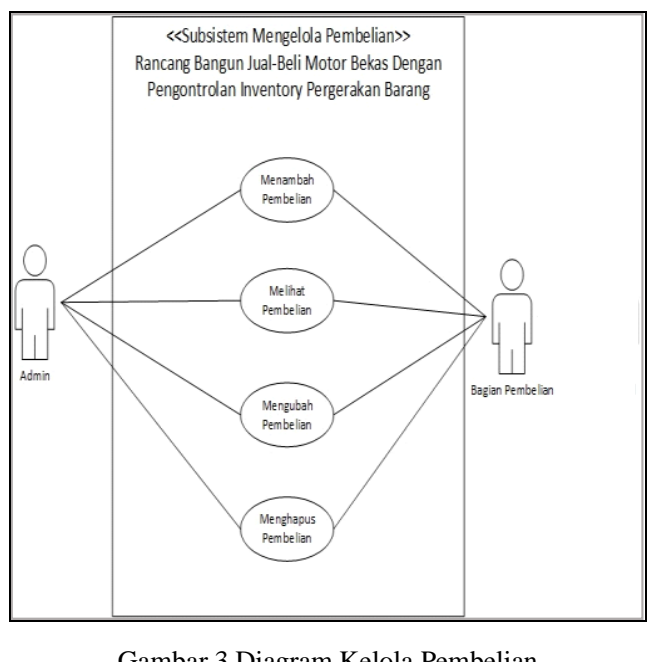

Gambar 3 Diagram Kelola Pembelian 


\section{c. UML- Diagram Kelola Data FSN}

Deskripsi: Mengelola data FSN motor bekas pada sistem, tampak pada Gambar 4. Aktor : Pengguna (admin), Bagian Pembelian, Penjual. Kondisi Awal : Admin memilih menu FSN motor bekas yang telah tersedia. Kondisi Akhir : Admin dan Bagian Pembelian dapat menggunakan fitur lihat data FSN motor bekas, tambah data FSN motor bekas, dan ubah FSN motor bekas yang terdapat dalam sistem.

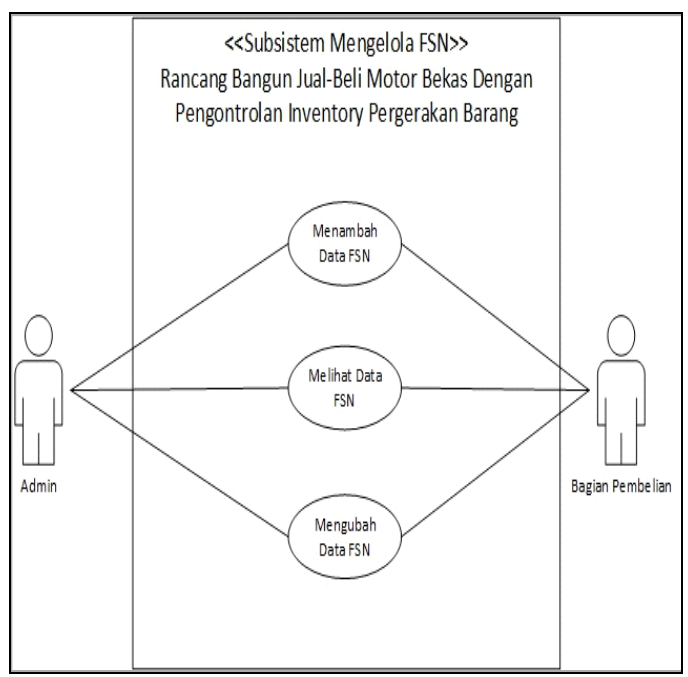

Gambar 4 Diagram Kelola FSN

\section{d. ERD (Entity Relationship Diagram)}

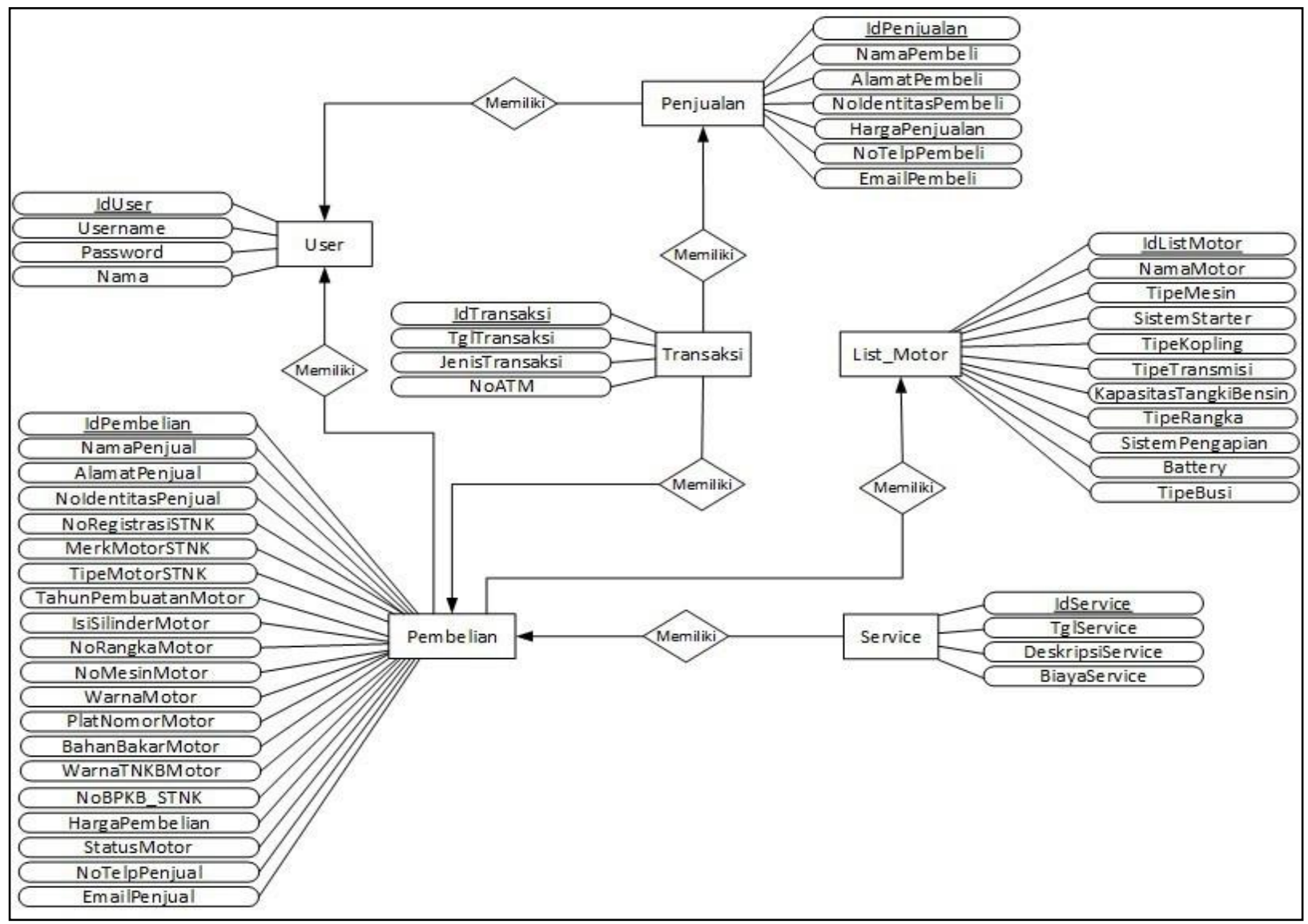

Gambar 5 Entity Relationship Diagram (ERD) 
Gambar 5 merupakan model basisdata menggunakan ERD, terdiri dari entitas User, Transaksi, Penjualan, Pembelian, List Motor dan Service Keterhubungan antar entitas digambarkan dalam bentuk belah ketupat, hubungan yang digunakan adalah 1 ke banyak atau (1-N).

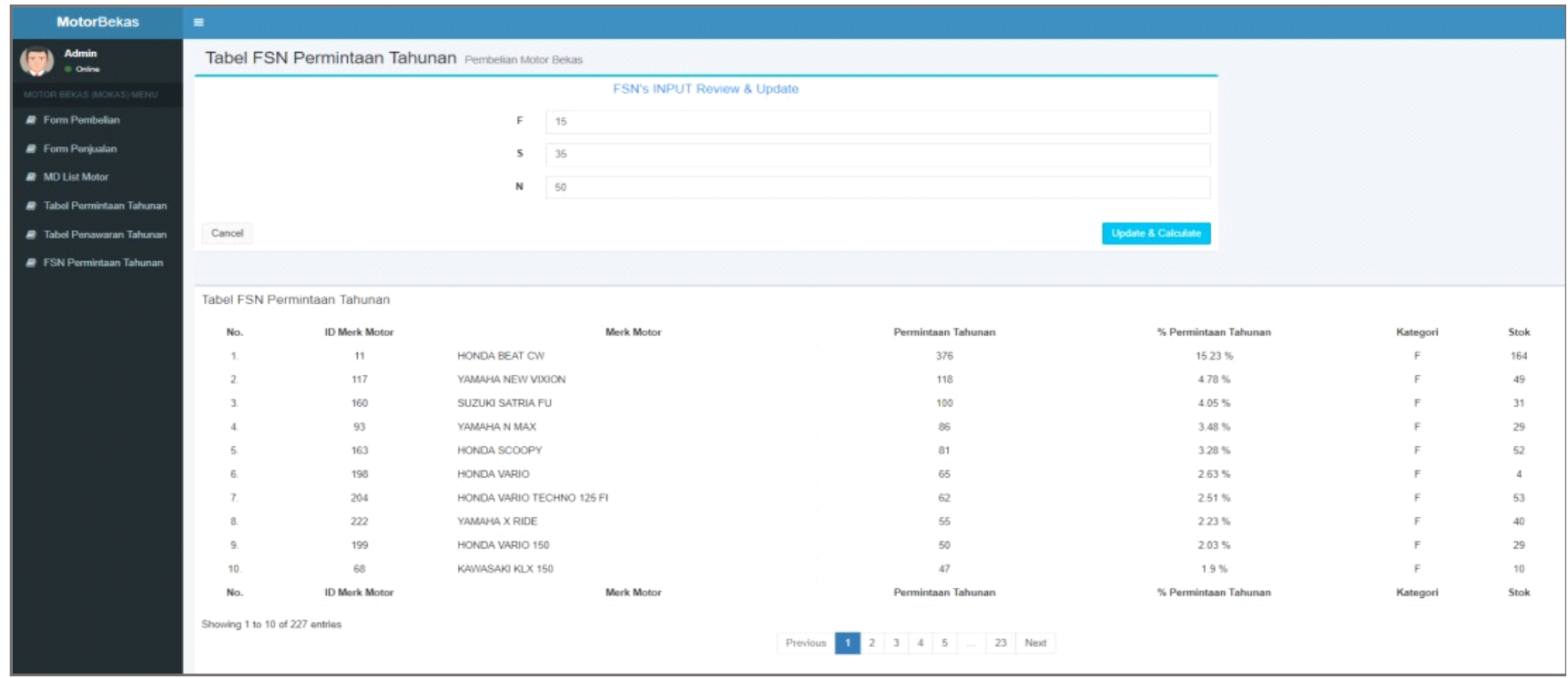

Gambar 6 FSN Permintaan Tahunan

\section{IMPLEMENTASI}

Bagian implementasi ini membahas mengenai antarmuka pengguna beserta panduan pengguna Sistem Informasi Penjualan-Pembelian dan Persediaan menggunakan Analisis FSN.

\section{A.Halaman Utama}

Berikut adalah tampilan halaman utama situs web saat pengguna masuk ke sistem, pada Gambar 7.

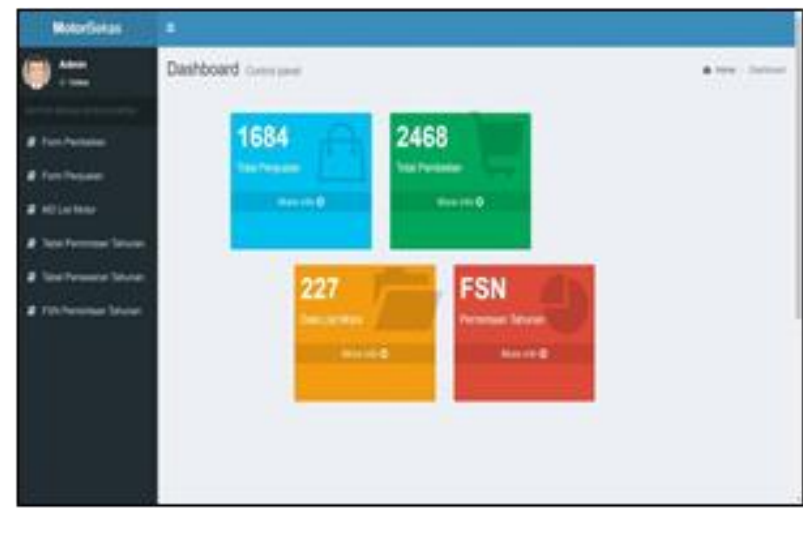

Gambar 7 Halaman Utama

\section{B. Form Pembelian}

Gambar 8 menampilkan form yang dapat digunakan oleh bagian pembelian motor bekas. Form ini digunakan untuk memasukkan data motor bekas yang dibeli untuk dijual kembali. Form ini mencatat detail motor yang dibeli, data penjual motor bekas, dan harga pembelian motor tersebut sehingga memudahkan pencatatan transaksi pembelian motor bekas.

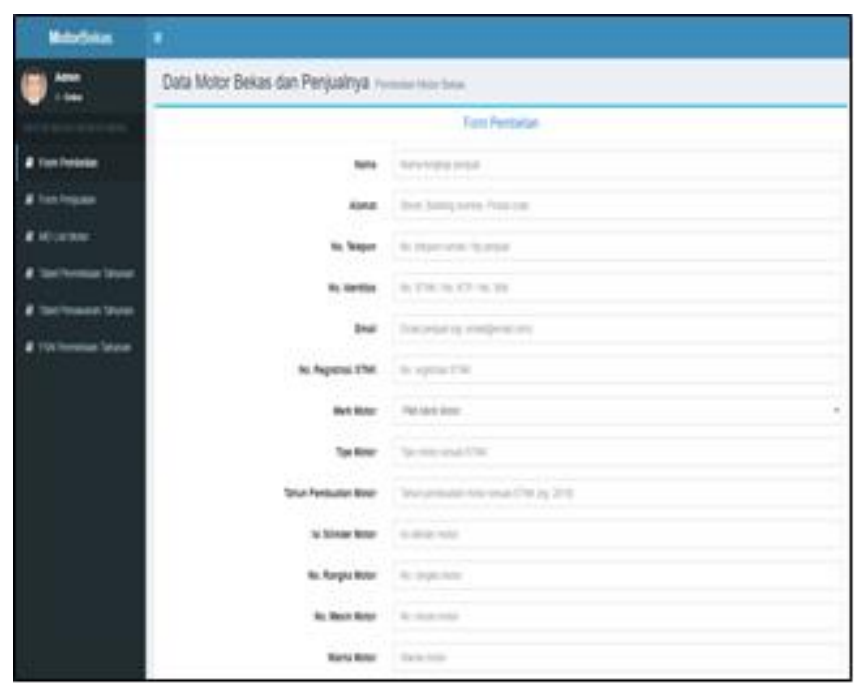

Gambar 8 Form Pembelian 1 


\section{Hasil Analisis FSN Permintaan}

Gambar 6 menampilkan daftar tipe motor yang ada pada database, pencatatan permintaan satu tahun kebelakang, kategori yang disesuaikan berdasarkan metode FSN [6], [7], dan jumlah stok barang yang tersedia di penyimpanan pada saat ini.

\section{Pengujian}

Pengujian sistem melalui kuesioner, dilakukan kepada user 1 (bagian penjualan) dan user 2 (bagian pembelian), tentang Kemudahan Program bernilai 8,25 dari rentang nilai 1 sampai dengan 10 dan Fungsi Program bernilai 8 (rentang 1 - 10), seperti pada Gambar 9.

\begin{tabular}{|l|r|r|r|}
\hline \multicolumn{1}{|c|}{ Indikator } & User 1 & User 2 & Rata-rata \\
\hline Kemudahan Program & Nilai (1-10) & Nilai (1-10) & \\
\hline 1 Kemudahan Pemakaian Program & 8,5 & 8 & 8,25 \\
\hline 2 Kemudahan Memilih Menu Program & 8 & 7 & 7,5 \\
\hline 3 Kemudahan Berinteraksi Dengan Program & 8 & 8 & 8 \\
\hline 4 Kemudahan Masuk Dan Keluar Dari Program & 9 & 8 & 8,5 \\
\hline Fungsi Program & 9 & 9 & 8 \\
\hline 5 Form List Motor & 8 & & 8 \\
\hline 6 Form Penjualan & 8 & 8 & 8 \\
\hline 7 Form Pembelian \& Analisis FSN & 8 & 8 & 8 \\
\hline & 8 & 8 & 8,125 \\
\hline
\end{tabular}

Gambar 9 Pengujian Sistem

\section{SIMPULAN}

Dari hasil pengujian yang telah dilakukan dengan data yang ada, dapat ditarik beberapa kesimpulan, yaitu Pengembangan Sistem Informasi Pembelian Penjualan, dan Persediaan menggunakan Analisis FSN, berbasis web mampu berfungsi sebagai sarana penunjang komputerisasi bagi perusahaan jual beli motor bekas dalam mengelola usahanya. Berdasarkan hasil percobaan diperoleh bahwa sistem yang dibangun telah mampu mengelola data transaksi pembelian, penjualan, dan persediaan dengan analisis menggunakan metode FSN.

Berdasarkan hal-hal yang telah tercapai pada implementasi, beberapa saran yang diharapkan dapat memberikan manfaat untuk pengembangan sistem ke depan, yaitu penambahan perhitungan biaya pada proses perbaikan motor (jika ada) untuk memudahkan bagian penjualan menentukan harga jual tanpa harus khawatir merugi dikarenakan biaya perbaikan yang terabaikan dan mempercepat proses perhitungan FSN sehingga menghemat waktu.

\section{DAFTAR PUSTAKA}

[1] M. Fathoni dan B. E. Purnama, I. U. Wardati, "Pembangunan Sistem Informasi Penjualan Sepeda Motor Bekas Pada Unit Dagang (Ud) Merdeka Motor Pacitan”, IJNS, vol. 2, no.3, pp. 46-50, Jul. 2013.

[2] Minarni dan B. Antoni, "Perancangan Aplikasi Penjualan Mobil Bekas Di CV. Shandy Motor Berbasis Web", TEKTOIF, vol. 1, no. 2, pp.13-19, Okt. 2013.

[3] H. Wimmie dan S. F. Kristian, "Sistem Informasi Penjualan Sepeda Motor Bekas Menggunakan Algoritma C4.5", JUISI, vol. 01, no. 02, pp. 151-156, Agu. 2015.

[4] D. Janari, M. M. Rahman, dan A. R. Anugerah, "Analisis Pengendalian Persediaan Menggunakan Pendekatan Music 3D pada Warehouse Di PT Semen Indonesia (Persero) Tbk Pabrik Tuban", TEKNOIN, vol. 22, no. 4, pp. 262-268, Des. 2016

[5] M. Hudori dan N. T. B. Tarigan, "Pengelompokan Persediaan Barang dengan Metode FSN Analysis (Fast, Slow and Non-moving) Berdasarkan Turn Over Ratio (TOR)", Jurnal Citra Widya Edukasi, vol. 11, no. 2, pp. 205-215, Agu. 2019.

[6] G. Brindha, "Inventory Management". International Journal of Innovative Research in Science, Engineering and Technology, vol.3, no.1, pp. 8163- 8176, 2014.

[7] Y. Kumar1, R.K. Khaparde, K. Dewangan, G. K. Dewangan, J. S Dhiwar dan D. S. Kumar, "FSN Analysis for Inventory Management-Case Study of Sponge Iron Plant". International Journal for Research in Applied Science and Engineering Technology, vol. 5, no. 2, pp. 53-57, 2017.

[8] S. Mitra, M. S. Reddy, dan K. Prince, "Inventory Control Using FSN Analysis - A Case Study on a Manufacturing Industry", IJISET, vol. 2, no. 4, pp. 322-325, April 2015.

[9] R. E. Indrajit dan R. Djokopranoto, Manajemen Persediaan. Jakarta: Grasindo, 2003.

[10] J. Rumbaugh, G. Booch dan I. Jacobson, The Unified Modelling Language Reference Manual, Addison-Wesley, 2005.

[11] M. J. Chonoles dan J. A. Schardt, UML 2 for Dummies, New York: Wiley Publishing, 2003.

[12] J. Arlow dan I. Neustadt, UML and the Unified Process, London: Pearson Education Limited, 2002.

[13] A. Lieberty dan R. V. Imbar, "Sistem Informasi Meramalkan Penjualan Barang Dengan Metode Double Exponential Smoothing (Studi kasus: PD. Padalarang Jaya)," Jurnal Teknik Informatika dan Sistem Informasi, vol. 1, no. 1, p. 27-32, Apr. 2015. 